\section{Innovative Electrically Conductive Adhesives: Nickel-Free and Cost-Effective}

\begin{abstract}
$A^{\text {new }}$ new product on the market is an electrically conductive adhesive developed by Polytec PT, which is formulated with a nickel-free filler and exhibits properties that are certainly comparable with those of standard silver conductive adhesives.
\end{abstract}

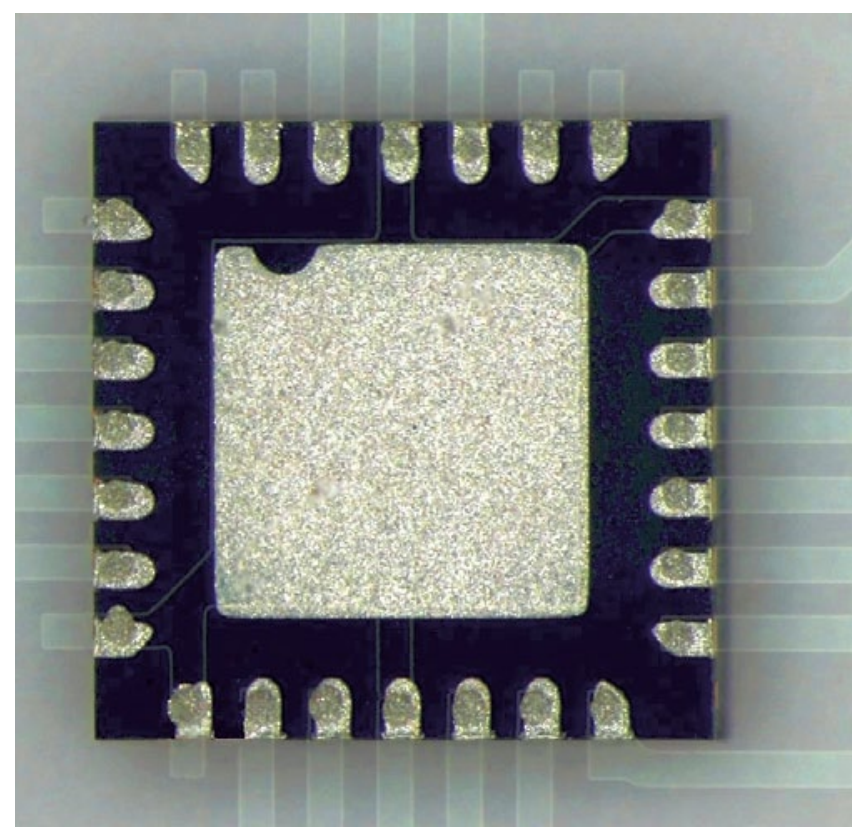

trical conductivity for epoxy resins, which otherwise have an insulating effect. Typically, such adhesives feature a volume resistivity of $10^{-3}$ to $10^{-4} \Omega-\mathrm{cm}$. Polytec EC 275 is formulated without silver flakes and instead uses a nickelfree filler from European production.

This alternative adhesive is not only substantially less expensive than standard silver adhesives, its raw material costs no longer directly depend on highly volatile precious metal market prices and dollar exchange rates, which, in addition to lower overall procurement costs, results in a more constant price and therefore to

Electrically conductive adhesives have been widely used for a long time in the production of electronic components. The applications are as numerous and varied as the advantages of electrically conductive adhesives themselves, whether it is for SMD bonding or contacting RFID antennas. Special production processes in microelectronics, such as flip-chip assembly, were developed specifically for the use of electrically conductive adhesives, without which many complex circuits would not have been possible in the first place.

Usually, the electrically conductive adhesives used today are based on epoxy resins with a low ionic content and are filled with 70-80\% fine silver powder. This ensures very good elecucts with a silver filler.

Polytec EC 275 is suitable for such applications as IC packaging, hybrid and SMD bonding, contacting RFID antennas and EMI/RF shielding. The pastelike adhesive can be easily applied with various dispensing techniques, screen printing or manually. Like most twocomponent adhesives from Polytec PT, the new adhesive is also available premixed in frozen syringes.

For further information, please contact: Polytec PT GmbH, D-76337 Waldbronn, www.polytec-pt.de, info@polytec-pt.de

\section{Evacuation System Prevents Air Bubbles Forming}

T he EG 30 evacuation system from VA$\mathrm{Tec}$ is ideal for use where the rapid, reliable and controlled degassing of components is required in production processes. For example, it can be used to degas microcircuits that have been encapsulated in silicone gel or epoxy resin. This allows the air bubbles that have formed during the encapsulation process and which could damage the components to be removed reliably.

The evacuation system exposes the microcomponents to a specific vacuum. Before the degassing process starts, the components are placed in a vacuum chamber in batches of up to 300 items. As the processes are heavily dependent on the encapsulation material used, the parameters are user configurable. If required, they can also be

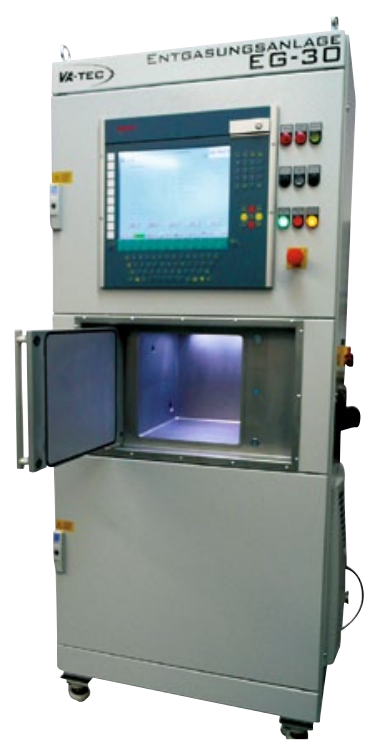

saved in in-

dividual programmes and recalled at the press of a button. Both the evacuation process (downstream control) and the subsequent controlled ventilation of the chamber (upstream control) can be precisely regulated. As a result, the entire process can be quickly adapted to the application in question and the process is fully reproducible.

For more information, please contact:

VA-Tec GmbH \& Co KG, D-97877

Wertheim, Germany, www.va-tec.de 